\title{
An Evolutionary Perspective on Substance Abuse
}

\author{
Randolph M. Nesse
}

Department of Psychiatry, University of Michigan, Ann Arbor, Michigan

This article describes how recent advances in understanding the evolutionary functions of emotions can help to reconcile diverse approaches to substance abuse. Emotions can be understood as specialized states that prepare individuals to cope with opportunities and threats. Drugs that artificially induce pleasure or block normal suffering disrupt these evolved mechanisms, and thus should tend to interfere with adaptive behavior, even if the drugs are medically safe. Nonetheless, we routinely use drugs quite safely to block defenses like pain, cough, and anxiety. This apparent contradiction is explained by the relatively small costs of defenses compared to the potentially huge costs of not expressing a defensive response when it is needed. An evolutionary perspective has implications for substance abuse research, treatment, and social policy. This perspective suggests that the search for etiology needs to address the human tendency to abuse drugs separately from individual differences in these tendencies, that clinical treatments that take account of the broad range of patients' emotional life are well justified, and that social policies need to address substance use and abuse not as diseases to be cured but as human tendencies that need to be managed. To prepare for future drugs that will likely alter emotions safely, we urgently need a better understanding of the adaptive function of the emotions.

KEY WORDS: Substance abuse; Evolution; Adaptation; Drugs; Psychiatry

\section{INTRODUCTION}

Over 18,000 articles have been published about substance abuse in the past 25 years. Despite this huge outpouring of facts and theory, fundamental questions remain unresolved (Shaffer 1986; Brower et al. 1989). Disagreements continue concerning whether substance abuse is a disease, a behavior, a psychological problem, a social problem, or a moral issue. Arguments rage over such issues as whether substance abuse is caused mainly by genetic factors, life experi-

Received December 16, 1993; revised September 17, 1994.

Address reprint requests and correspondence to: Randolph M. Nesse, M.D., Department of Psychiatry, University of Michigan, Med-Inn Building, Room C440, Ann Arbor, MI 48109-0840, U.S.A., randolph.nesse@med.umich.edu 
ences, social situations, or some combination. Divergent answers to these questions arise not so much from disagreement about facts but from different ways of thinking about substance abuse.

This article develops an evolutionary framework for thinking about substance abuse that can encompass otherwise divergent approaches. While natural selection has not directly shaped a trait that motivates substance abuse, it has shaped the behavior regulation mechanisms on which psychotropic drugs act, most specifically, the emotions. Understanding the origins and functions of emotional pleasures and pains leads to insights about why people use psychoactive substances. These insights have implications for treatment, research and public policy.

\section{THE EVOLUTION OF EMOTIONS}

The utility of the emotions as communications, motivations, and influences on future behavior has long been recognized, but a modern evolutionary approach specifies more precisely how the capacities for particular emotions increased the reproductive success of individuals in past generations. By emotion, I mean a pattern of coordinated changes in physiology, cognition, behavioral tendencies, and subjective experience that prepare an individual to cope especially well with a particular kind of situation. The capacities for emotions and their regulating mechanisms have been shaped by natural selection, which maximizes reproductive success, not survival (Daly and Wilson 1983), and maximizes individual fitness, not that of groups or species (Williams 1966; Dawkins 1976). It is widely recognized that emotional capacities evolved for life in hunter-gatherer bands and may be maladaptive in a modern setting (Konner 1983).

An evolutionary approach increasingly is providing a foundation for research on the emotions (Plutchik and Kellerman 1980; McNaughton 1989; Nesse 1990). Previously, many authors tried to specify the adaptive function for each emotion, just as one would for the turtle's shell or the bluebird's song. For instance, fear was said to motivate avoidance of danger, and romantic love to increase the success of courtship. Such explanations are limited, however, because one emotion may serve many functions (e.g., fear causes physiological arousal, communicates danger to others, inhibits socially unacceptable behavior, and motivates escape and avoidance), and several emotions may unite to serve one function (e.g., fear, envy, and anger combine to prevent the loss of a mate). Emotions are different from other traits in that they correspond not to specific functions but to specific situations. They have been shaped by the adaptive challenges of certain situations that have repeatedly influenced fitness during the course of evolution.

An important characteristic of the emotions is that they are all, to some degree, pleasurable or painful. There are no hedonically neutral emotions because the force of natural selection acts only when fitness is increased or decreased. In general, opportunities and satisfactions induce pleasure, and 
threats and losses induce pain. People abuse drugs mainly to seek pleasure and to avoid pain. Understanding the adaptive significance of painful and pleasurable aspects of the emotions is an essential first step for understanding why people abuse drugs and how drug use interferes with adaptation.

\section{PAIN, PLEASURE, AND DRUGS}

The aversiveness of painful emotions motivates escape from danger and avoidance of threats. Physical pain motivates withdrawal from situations that are damaging bodily tissues, and the arousal associated with pain mobilizes the ability to escape and prevents reoccurrence. Congenital lack of capacity for pain is a serious handicap that results in severe orthopedic problems in early adulthood (Osuntokun et al. 1968). Diarrhea expels toxins from the gastrointestinal tract. Patients with shigellosis who receive antidiarrheal drugs have slower recoveries and more complications (DuPont and Hornick 1973). Cough clears foreign material from the respiratory tract. A depressed cough reflex increases susceptibility to pneumonia. Each of these capacities is aversive, but useful. Blocking such defensive responses generally decreases fitness (Williams and Nesse 1991).

The aversive emotions seem to serve similar functions. Fear, guilt, anger, grief, and low mood protect against threats to relationships, resources, and social status, in addition to threats to bodily integrity (Thornhill and Thornhill 1989). Social dangers reduce reproductive success by their influence on mating opportunities and position in the group. Impairment of the capacities for mental pain is often maladaptive. For instance, a person without the capacity for fear would not likely survive long among the predators on the savannah (Marks 1987). Phobic avoidance of the rock that last month hid a tiger might seem senseless, but would nonetheless be wise if there is even a small chance that the tiger is there again. We usually experience some anxiety because most of the time we face some threat or another. Calm contentment is not the normal state of the organism.

Experiences that tend to increase Darwinian fitness tend to arouse pleasure, and pleasure tends to generate future actions that repeat such experiences (Nesse 1990). Good food, sex, friendship, having children, being admired, having insight-these experiences bring pleasure, and people who successfully pursue them have a reproductive advantage. Psychoactive drugs short-circuit these evolved mechanisms. Cocaine and opium by-pass perception and cognition to directly stimulate the brain mechanisms that regulate pleasure. The mind signals that this experience is strongly increasing fitness, hence the tendency to repeat such experiences. Compared to such pleasure, most ordinary life satisfactions are feeble. Furthermore, continued drug use both desensitizes brain pleasure mechanisms and disrupts normal behavior regulation mechanisms; so ordinary life becomes doubly less rewarding. Compared to what everyday life can offer, satisfactions provided by drugs become greater and 
greater, in the well-known feedback spiral of chronic substance abuse (Alexander and Hadaway 1982, p. 376).

\section{WHY NOT USE DRUGS?}

"If drugs make people feel better, why not use them?" It is a fair question, and one that substance abusers often ask. They receive many answers. Drugs can cause disease or death or brain damage. Drugs are addicting and become the center of the user's existence. Drugs have withdrawal effects. Such answers emphasize addiction and medical dangers. Are these the only reasons not to use drugs? As new agents without these dangers become available, will there be any medical reasons to avoid their use?

An evolutionary view emphasizes a different danger. In a manner of speaking, drugs are like magnets near the compass of the mind. Any drug that disrupts the emotional guidance system shaped by natural selection an be expected to impair the person's ability to behave adaptively. No matter how medically safe and nonaddicting, all psychotropic drugs should, for this reason alone, be considered potentially harmful.

\section{OVERPROTECTIVE MOTHER NATURE}

How, then, can we explain the seeming safety of many drugs? Many drugs we take for everyday ailments-cough, fever, pain, nausea, and diarrhea-seem to cause little harm. And caffeine, alcohol, and nicotine in moderate amounts seem not to interfere with our ability to act adaptively. In fact, they can increase our ability to perform certain tasks (Hanna and Hornick 1977; Pomerleau and Pomerleau 1987; Thayer 1989). If these drugs block normal evolved systems, why don't they cause harm?

Consider the selective forces that shaped the regulation of defensive responses. Every control system makes some errors of excessive response and some errors of deficient response. Defenses are usually inexpensive, while failure to express a defense when it is needed can be catastrophic. Natural selection therefore tends to shape control mechanisms that err on the side of over-responsiveness for inexpensive actions that may prevent great harm. This is why cough suppressants, aspirin, and antianxiety agents can so often be used safely.

A slightly different argument applies to pleasure. While it is important that positive emotions usually accompany behaviors that increase fitness, occasional impairment of pleasure is not catastrophic. If, however, intense pleasure accompanies behaviors that don't increase fitness, much time and effort may be wasted. Modern life provides so many such pleasures-playing video games is an example--that we tend not to recognize that the pleasure they provide is artificial and usually unrelated to fitness.

Selection seems to have created a mind that cannot be satisfied. We no 
sooner accomplish one goal than satisfaction fades and we are driven towards another. It is possible to get enough food and water, for a time, at least, but no amount of social status seems to be enough. To the extent that status increases fitness, genes that code for acting in ways that increase status will tend to spread; genes that result in lack of such striving will be gradually eliminated. The systems that motivate us were shaped to benefit our genes, not our selves. Our minds were shaped to maximize fitness, not happiness.

\section{ETIOLOGY OF SUBSTANCE ABUSE}

An evolutionary framework suggests that two separate questions need to be asked about the etiology of substance abuse: (1) Why do all humans have the capacity for substance abuse? (2) Why do people differ in their susceptibility to substance abuse?

An answer to the first question is straightforward: We all have a capacity for substance abuse because our motivational systems can be directly influenced by chemicals (Frye 1980). The seeking of certain chemicals is one manifestation of the generally adaptive tendency to repeat behaviors that bring pleasure. In this sense, trying to explain why humans use drugs is like trying to explain why people eat. The difference, of course, is that food intake is useful and selection has shaped specialized brain mechanisms that regulate food intake, while no mechanisms have evolved specifically to regulate psychotropic drug intake. An evolutionary view supports Siegel's suggestion that substance abuse is best approached as a normal human tendency, but it flatly contradicts his suggestion that drug seeking is a "fourth drive" (Siegel 1989).

In the debate about whether substance abuse should be considered a medical disease, an evolutionary view supports a medical model in that substance abuse is not just socially unacceptable, but is biologically maladaptive. Also, patterns of substance abuse can be viewed as syndromes with typical courses that result from exposure to novel agents. However, as we shall see, an evolutionary approach also suggests that the search for a specific medical etiology for substance abuse may well prove fruitless.

\section{INDIVIDUAL SUSCEPTIBILITY TO SUBSTANCE ABUSE}

Differences in individual susceptibility to substance abuse result in part from genetic differences. Twin studies (Goodwin 1986), family history studies (Cloninger 1981), and adoption studies (Schuckit 1985) show an increased risk of substance abuse for male offspring of alcoholics. Being raised by an alcoholic parent seems not to increase the risk, but the genetic offspring of alcoholics have alcoholism rates four times as high as those in the general population, even when they are reared in a nonalcoholic family (Goodwin). In a prospective study, the quality of the childhood environment, I.Q., and the parental social class were extremely weak predictors of adult alcohol abuse, 
while a family history of alcoholism and the absence of Mediterranean ancestry were strong predictors (Vaillant 1983). One study is currently following 470 men from their college years through midlife to determine the factors that predict substance abuse (Schuckit 1987). Those with a strong family history of alcoholism have relatively reduced reactions to alcohol intake in the laboratory, but data on their relative rates of alcoholism are not yet available.

Although criticism of the methods and conclusions of the studies cited above makes their significance uncertain (Murray et al. 1983; Searles 1988), genetic factors certainly do influence individual susceptibility to substance abuse. This does not mean however, that substance abuse is a "genetic disease." Many inherited characteristics could increase susceptibility to substance abuse, including differences in emotional reactions to different substances, ability to control impulses, abilities to get satisfactions in socially acceptable ways, tendencies to low mood or anxiety, and susceptibility to social influences. Personality traits are moderately heritable (Plomin et al. 1980), and it would be surprising if they did not contribute to the heritability of substance abuse. In the natural environment, which does not offer access to a variety of concentrated drugs and routes of administration, most people with traits that increased the tendency to substance abuse would not have any substance abuse disorder. Even if specific genes are found to predispose some people to substance abuse (Mullen 1989), these will not be "genes for substance abuse" but genes that have been selected because they offer some kind of benefit, perhaps a benefit entirely distinct from behavioral regulation.

In certain populations, selection may have shaped protection against alcoholism. Low rates of alcoholism in Orientals have been altributed to a change in a single gene nucleotide. This change makes an inactive form of alcohol dehydrogenase so that drinking results in the rapid accumulation of toxic acetaldehyde, which causes nausea and vomiting like that caused by Antabuse (Smith 1986; Mullen 1989). It is difficult to say if this characteristic is an adaptation shaped by natural selection in Orientals, or merely a quirk that is adaptive. More clear is the selective force of alcohol preference today. Alcohol-caused motor vehicle accidents are a major cause of death in the early reproductive years, so natural selection should gradually decrease the human preference for alcohol. The time course of changes from natural selection is so slow, however, that cars will likely be extinct before such selection eliminates our taste for alcohol.

\section{CLINICAL IMPLICATIONS}

The greatest clinical benefit of an evolutionary view of substance abuse may be its explanation of why drug use is often inadvisable, even when it is not addicting or medically dangerous. Some patients will be helped by knowing that psychotropic drugs interfere with the evolved mechanisms that regulate behavior. 
An evolutionary perspective also supports the principle that cessation of drug use is, as many clinicians have long recognized, the first step in treatment. Whatever methods accomplish abstinence-behavioral, psychotherapeutic, and social-are indicated. Also indicated are more general strategies that increase the person's ability to get normal satisfactions from social life. Bad feelings, and lack of good feelings, are significant factors in the return to drug use. Helping people to feel better, whether by psychotherapy, marital counselling, employment change, or the use of medications, is essential, not adjunctive treatment. An evolutionary view also supports matching different treatments to the needs of individual patients (Brower 1989). Finally, it encourages both clinician and client to view some suffering as normal and even useful.

There are also implications for the use of psychotropic drugs in general. Some people say new drugs will bring an age of human happiness, while others oppose almost all psychotropic drug use. Although an evolutionary perspective tends to support the conservative side of this argument, it also can specify some situations in which drug use is clearly warranted.

First, there are situations, already discussed, in which defensive systems overreact. Dampening the responses of these systems can sometimes relieve suffering with little risk. The use of benzodiazepines to control anxiety would be a perfect example, except for the major problems of dependence and withdrawal.

Psychotropic drugs are also appropriately used to block outmoded responses. Our minds were shaped for an environment vastly different from that in which we live. The constraints on aggression in a bureaucracy, the vicissitudes of modern marriages, the possibility of working long into the night-our emotions do not guide us reliably in these circumstances.

Drugs are also used to adjust arousal. Stimulants increase alertness for study or long-distance driving, and sedatives adjust sleep to changes in time zones (Thayer 1989). Such uses are exceptions to the principle that drugs are used for their subjective effects. In this case, they mainly adjust the timing of arousal to match the challenges of our unnatural world.

Drugs can also correct brain abnormalities. It remains difficult to tell, however, when psychotropic drugs are correcting neurophysiological abnormalities, and when they are simply blocking normal aversive emotions. It is tempting, but erroneous, to conclude that finding neurophysiologic correlates of a mental condition implies that the condition is caused by a brain abnormality. Many neurophysiologic correlates of mental states have nothing to do with the etiology of the state, they are merely aspects of the operation of normal brain mechanisms. Evidence of a "biological disorder" is not needed, however, to justify the drug treatment of mental distress. Psychiatry is, in this respect, like the rest of medicine. A general practitioner routinely diagnoses and treats conditions like fever and pain that do not represent any defect in the body, but only the arousal of normal defenses against infection or trauma. Drugs that dampen the body's defensive responses can often safely relieve discomfort, whether the response is cough, pain, anxiety, or sadness. 


\section{IMPLICATIONS FOR SOCIAL POLICY}

An evolutionary perspective suggests that it will be impossible to "solve the drug problem." Substance abuse is not a rare phenomenon of a few people in a few societies, but of many otherwise-normal people in most societies. Although a social phenomenon, it consists, ultimately, of the actions of individuals. A difficult responsibility of any government is to set and enforce rules about drug use. In modern Western society, this effort is particularly difficult because of our wealth, freedom, leisure, travel, and the constant discovery of new drugs and routes of administration.

Frustration about the failure to control drug use and recognition of the socially corrosive effect of a large illicit economy had led to calls for legalization of some abused substances (Nadelmann 1989). The tacit argument seems to be that society is paying too high a price for protecting deviant individuals from actions that harm mainly themselves. An evolutionary view suggests, however, that all of us, not just deviants, are susceptible to substance abuse and that legalization might result in substance abuse by many more people.

This view does not necessarily imply that legalizing certain drugs is unwise. The debate about how the law should view drug use should be based on controlled studies and pragmatic experience, not on the erroneous notions that substance abusers are fundamentally different from other people, that substance abuse is a genetic disease, or that substance abuse is created only by social environment. If drug abuse is seen as an intrinsic human tendency, instead of a disease with a specific explanation and a specific cure, then the control of substance abuse can be expected to require substantial and continuing public expenditures for a variety of interventions. Even modest control of drug use will need every available cost-effective strategy-education, establishment of social norms, treatment, police enforcement, legal sanctions, political influence on suppliers, and others still to be developed.

\section{THE FUTURE}

Although it seems that our society is awash with drugs, the drug age may just be beginning. Private entrepreneurs and pharmaceutical companies are steadily inventing new agents. Recently introduced antidepressants seem to induce confidence and a mild euphoria even in those without a depressive disorder. We will likely soon have drugs that relieve anxiety safely without the withdrawal and side effects that limit the use of present agents. Soon, we may have drugs that stop grief, increase self-esteem, arouse the feeling of love, and make people feel that their lives are more meaningful. Some argue that the invention of such drugs is the solution to our current dilemmas about substance abuse (Siegel 1989).

How will we make decisions about how to use these agents? Should we treat pcople with drugs whencver a safe agent is available that will make them 
feel better? Or, to put it more realistically, should society try to prohibit people from using such agents? Prepared or not, we soon will confront these questions. We will be better able to answer them if we have a deeper understanding of the evolutionary functions of the emotions.

This manuscript benefited substantially from comments from members of the Evolutionary Psychiatry Seminar at the University of Michigan, and from James Abelson, Cynthia Pomerleau, Nathan Wolf, and especially Fred Glaser and Helena Cronin. Its preparation was supported by the University of Michigan Evolution and Human Behavior Program.

\section{REFERENCES}

Alexander, B.K., and Hadaway, P.F. Opiate addiction: the case for an adaptive orientation Psychological Bulletin 92: 367-381, 1982.

Brower, K.J., Blow, F.C., et al. Treatment implications of chemical dependency models: an integrative approach. Joumal of Substance Abuse Treatment 6: 147-157, 1989.

Cloninger, C.R. Inheritance of alcohol abuse. Archives of General Psychiatry 38: 861-868, 1981.

Daly, M., and Wilson, M. Sex, Evolution, and Behavior, Boston: Willard Grant Press, 1983.

Dawkins, R. The Selfish Gene, Oxford: Oxford University Press, 1976.

DuPont, H.L., and Hornick, R.B. Adverse effect of Lomotil therapy in shigellosis. Journal of the American Medical Association 226: 1525-1528. 1973.

Frye, R.V. The sociobiological paradigni: a new approach to drug using behavior. Journal of Psychedelic Drugs 12: 21-25, 1980.

Goodwin, D.W. Genetic factors in the development of alcoholism. PCNA 9: 427, 1986.

Hanna, J.M., and Hornick, C.A. Use of cocoa leaf in southern Peru: adaptation or addiction? Bulletin on Narcotics 29: 63-73, 1977.

Konner, M. The Tangled Wing: Biological Constraints on the Human Spirit, New York: Harper Colophon Books, 1983.

Marks, I.M. Fears, Phobias, and Rituals, New York: Oxford University Press, 1987.

McNaughton, N. Biology and Emotion, Cambridge, England: Cambridge University Press, 1989.

Mullen, M. Alcoholism and the "new genetics." British Joumal of Addiction 84: 1433-1440, 1989.

Murray, R.M., Clifford, C.A., et al. Twin and adoption studies: how good is the evidence for a genetic role? Recent Developments in Alcoholism, New York: Academic Press, 1983.

Nadelmann, E.A. Drug prohibition in the United States: costs, consequences, and alternatives. Science 245: 939-946, 1989.

Nesse, R.M. Evolutionary explanations of emotions. Human Nature 1: 261-289, 1990.

Osuntokun, B.O. Odekı, F.I... et al Congenital pain asymoblia and auditory imperception. Journal of Neurology, Neurosurgery, and Psychiatry 31: 291-296, 1968.

Plomin, R., DeFries, J.C., et al. Behavioral Genetics: A Primer, San Francisco: W.H. Freeman, 1980.

Plutchik, R., and Kellerman, H. Theories of Emotion, Orlando: Academic Pres, Inc., 1980.

Pomerleau, O.F., and Pomerleau, C.S. A biobehavioral view of substance abuse and addiction. Journal of Drug Issues 17: 111-131, 1987.

Schuckit, M.A. Genetics and the risk for alcoholism. Journal of the American Medical Association 254: 2614-2617, 1985.

Schuckit, M.A. Biological vulnerability to alcoholism. Journal of Consulting and Clinical Psychology 55: 301, 1987.

Searles, J.S. The role of genetics in the pathogenesis of alcoholism. Journal of Abnormal Psychology 97: 153-167, 1988.

Shaffer, H.J. Conceptual crises and the addictions: a philosophy of science perspective. Journal of Substance Abuse Treatment 3: 285-296, 1986.

Siegel, R.K. Intoxication: Life in Pursuit of Artificial Paradise, New York: E.P. Dutton, 1989.

Smith, M. Genetics of human alcohol and aldehyde dehydrogenases. Advances in Human Genetics 15: 249-290, 1986. 
Thayer, R.E. The Biopsychology of Mood and Arousal, New York: Oxford University Press, 1989.

Thornhill, R., and Thornhill, N.W. The evolution of psychological pain. In Sociobiology and the Social Sciences. Lubbock, TX: Texas Tech University Press, 1989.

Vaillant, G.E. The Natural History of Alcoholism, Cambridge, MA: Harvard University Press, 1983.

Williams, G.C. Adaptation and Natural Selection: A Critique of Some Current Evolutionary Thought, Princeton, NJ: Princeton University Press, 1966.

Williams, G.W., and Nesse, R.M. The dawn of Darwinian medicine. Quarterly Review of Biology 66: $1-22,1991$. 